\title{
The validity of the Arabic Version of the University of Pennsylvania Smell Identification Test in Egyptian Population
}

\author{
Original Tarek A. Abd-Elhafez", Zeinab Abdel Aziz Kasemy**, Ahmad M. Hamdan* \\ Article \\ "Department of Otorhinolaryngology, Faculty of Medicine, Menoufia University, \\ ${ }^{* *}$ Department of Public Health and Community Medicine, Faculty of Medicine, Menoufia \\ University, Egypt.
}

\begin{abstract}
Objective: To assess the validity of the Arabic version of the University of Pennsylvania Smell Identification Test in the Egyptian population.

Patients and Methods: This was a cross sectional study including 124 normal Egyptian subjects. Socioeconomic standard was assessed, and patients were categorized into three categories; low, moderate and high socioeconomic levels. The total number of correct answers for the 40 odorants presented was used to determine the test score. The difficulty level of the test was checked by a visual analogue scale. The percentage of the study sample detecting every odor was calculated. Internal consistency of the test was checked by cronbach's alpha test.

Results: The study group included 87 females and 37 males with a mean age of $29.28 \pm 5.92$ years. The average smell identification test score for all participants was $31.49 \pm 1.74$. The average visual analog scale score for ease of applicability of the test was $7.13 \pm 0.58$ with no significant difference between males and females. The smell identification test score was higher among males than females with little significance. Participants with high and moderate socio-economic standards reported significantly higher test score. Thirty-one odors were correctly identified by at least $70 \%$ of the volunteers, Overall alpha was 0.749 .

Conclusion: The Arabic version of University of Pennsylvania Smell Identification Test is an adequate tool for assessment of olfaction in the Egyptian population. But 9 Odorants of this test needs further revision. Males and higher socioeconomic levels were associated with better test results.
\end{abstract}

Key Words: Arabic, Egypt, olfaction, olfactory test, University of Pennsylvania smell identification test.

Received: 23 June 2020, Accepted: 31 August 2020

Corresponding Author: Ahmad M. Hamdan, MD, Department of Otorhinolaryngology, Faculty of Medicine, Menoufia University, Egypt., Tel.: 0020482230290, E-mail: Ahmed.Hamdan@med.menofia.edu.eg

ISSN: 2090-0740, November 2020 Vol.21, No.3

\section{INTRODUCTION}

The University of Pennsylvania Smell Identification Test (UPSIT) is one of the most widely used tests to assess the olfactory function. It is commercially known as the smell identification test (Sensonics Inc. $)^{[1]}$. The test has been translated into 29 languages and accents according to the manufacturing company including Arabic. ${ }^{[2]}$ Several factors have an impact on the olfactory function including age. Decreased olfactory function is very common in the older population, being present in over half of those between the ages of 65 and 80 years and in over three quarters of those over the age of 80 years ${ }^{[3]}$. There are certain sex differences in olfactory performance. Although significant, the effects were notably small with very low absolute differences in olfactory test performance ${ }^{[4]}$. Air pollution which is more common in industrial countries and urban communities, is associated with olfactory dysfunction and olfactory bulb pathology $y^{[5]}$. Age and gender distribution, and degree of air pollution differ between different populations with their reflection on olfactory function. This necessitates adjustment of the odorant molecules in olfactory test materials adapted for use in every population. Cultural and socioeconomic factors have necessitated changes in the original version of the UPSIT on conversion to different languages. The odorant items and the response alternatives have been changed in some foreign-language versions to make the test scores more congruent with North American norms and to prevent the cultural bias. ${ }^{[2]}$ Similarly, the Arabic version of UPSIT was created by changing the language and odors to be more familiar for Arab nation. Although the Arabic version of the UPSIT has been available for some time, few attempts have been made to assess its validity in the Arabic population including the study by Albaharna et $a^{[6]}$. The present study attempted to assess the validity of the Arabic version of the UPSIT in the Egyptian population. 


\section{PATIENTS AND METHODS:}

The current study was a cross sectional study conducted at Otorhinolaryngology department, Faculty of Medicine, Menoufia University after approval of the institutional review board of the faculty and a written consent was taken from every subject before participation in the study. The study included 124 normal adult Egyptian subjects who were chosen randomly from the community. No participant had any olfactory complaints. Patients with neurological diseases, a history of cranial trauma or upper airway infection on the day of the test were excluded from the study. Socioeconomic standard (SES) was assessed by updated scaling score of SES developed by Fahmy et al ${ }^{[8]}$. According to this score, patients were categorized into three categories; low, moderate and high socioeconomic levels. In our study, the test administration was supervised by one of the authors to ensure adequate application of the test. The UPSIT (produced by Sensonics, Inc., Haddon Heights, NJ) consists of 4 envelope-sized booklets, each containing 10 "scratch and sniff" odorants. The odorants are embedded in 10- to 50-m microcapsules, which are contained in a 13-38 $\mathrm{mm}$ brown rectangular area positioning at the bottom of each strip (Figure 1). The odorant is released by scratching the brown area with a pencil tip in a standardized manner. Each odorant strip has a multiple-choice question with four alternatives. The test is based on forced choice technique. For each odorant, subjects are presented with four odor names and are asked to select the correct answer even if no smells perceived. The total number of correct answers for the 40 odorants presented was used to determine the UPSIT score. According to the test guide, scores of 6 to 18 are considered as anosmia, scores of 19 to 25 are considered as severe hyposmia, scores of 26 to 29 are considered as moderate hyposmia, scores of 30 to 33 are considered as mild hyposmia, and scores more than 33 are considered as normosmia. In the Arabic version of the UPSIT, the language was changed to Arabic and 14 odors from the original were replaced by odors that are more familiar with the Arabic population (Table 1). The difficulty level of the Arabic version of the UPSIT was checked by a visual analogue scale (VAS) which consisted of 10 points score with 1 indicating an extremely difficult test and 10 indicating an extremely easy test. internal consistency and reliability of the test items was calculated. The primary outcome measures include the average UPSIT score and VAS score for difficulty of the test for the study sample, and the percentage of the study sample detecting each odor of the 40 odors of the test was calculated. Secondary outcome measures include comparison between males and females regarding UPSIT and VAS scores and between the three categories of SAS regarding UPSIT score. Also they include the assessment of the alpha value for reliability of the test.

\section{Sample size:}

Based on past review of literature, Doty, 2001 $1^{[7]}$ reported that the cutoff point criterion used by Doty in the validation of each odor was $70 \%$ of correct rates. Sample size has been calculated at $\alpha=0.05$, CI95\% and it was 124 participants.

\section{Statistical Analysis:}

Results were statistically analyzed by SPSS version 20 (SPSS Inc., Chicago, IL, USA). Student's t-test was used for comparison of 2 means. ANOVA was used to compare between more than 2 means. $P$ value $<0.05$ was considered significant. Cronbach's alpha test was used to assess the internal consistency and reliability of the test items.

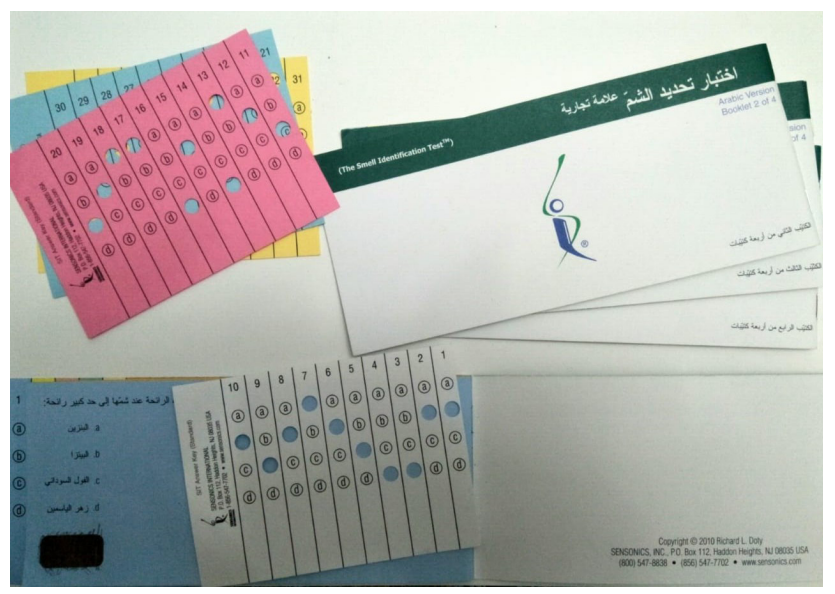

Fig. 1: Arabic version of University of Pennsylvania Smell Identification Test (UPSIT)

Table 1: English and Arabic version of UPSIT:

\begin{tabular}{ccc}
\hline No. & Odor in English version & Odor in Arabic version \\
\hline 1 & Pizza & Pizza \\
2 & Bubble-gum & Gum \\
3 & Menthol & Peppermint oil \\
4 & Cherry & Fish \\
5 & Motor oil & Motor oil \\
6 & Mint & Mint \\
7 & Banana & Banana \\
8 & Clove & Clove \\
9 & Leather & Leather \\
10 & Coconut & Coconut \\
11 & Onion & Onion \\
12 & Fruit punch & Drink fruit \\
13 & Licorice & Children powder \\
14 & Cheddar cheese & Cheese \\
15 & Cinnamon & Cumin \\
16 & Gasoline & Benzene \\
17 & Strawberry & Strawberry
\end{tabular}




\begin{tabular}{lcc}
\hline 18 & Cedar & Garlic \\
19 & Chocolate & Chocolate \\
20 & Gingerbread & Walnut \\
21 & Lilac & Grapefruit \\
22 & Turpentine & Rubber framework \\
23 & Peach & Peach \\
24 & Root beer & Coffee \\
25 & Dill pickle & Dill pickle \\
26 & Pineapple & Pineapple \\
27 & Lime & Apple \\
28 & Orange & Orange \\
29 & Winter green & Pine \\
30 & Watermelon & Watermelon \\
31 & Paint thinner & Jasmine flower \\
32 & Grass & Grass \\
33 & Smoke & Smoke \\
34 & Pine & Cardamom \\
35 & Grape & Grape \\
36 & Lemon & Lemon \\
37 & Soap & Soap \\
38 & Natural gas & Natural gas \\
39 & Rose & Rose \\
40 & Peanut & Peanut \\
\hline & & \\
\hline 3 & &
\end{tabular}

\section{RESULTS:}

A total of 124 volunteers were invited. The study group included 87 females and 37 males with a mean age of $29.28 \pm 5.92$ years. The average UPSIT score for all participants was $31.49 \pm 1.74$. The average VAS score for ease of applicability of the test was $7.13 \pm 0.58$. Using UPSIT, 20 subjects $(16.1 \%)$ had normal smell with score more than 33, 95 subjects $(76.6 \%)$ had mild hyposmia with scores from 30 to 33 , and 9 subjects $(7.3 \%)$ had moderate hyposmia with scores less than 30 . Thirty-one odors were correctly identified by at least $70 \%$ of the volunteers, whereas 9 odors were identified correctly by less than $70 \%$ of the respondents. The least identifiable odors were fish (identified by $3.2 \%$ of subjects) and dill pickle (identified by $14.5 \%$ of subjects) (Table 3 ). There was no significant difference between males and females regarding VAS for difficulty in dealing with the test $(P=0.924)$. UPSIT was higher among males than females with little significance $(31.89 \pm 1.21$ vs. $31.32 \pm 1.90$, $p=0.049$ ) (Table 2). Participants with high and moderate socio-economic standard reported significantly higher UPSIT than those with low socio-economic standard $(31.75 \pm 1.38$ and $31.94 \pm 2.51$ vs. $29.64 \pm 1.45, p<0.001)$ (Figure 2). Overall alpha was 0.749 . Item analysis of UPSIT revealed that some odors like pizza, leather and rose will increase the reliability of the test if deleted (Table 4).
Table 2: Percentage of subjects that answer each Smell Identification Test item correctly:

\begin{tabular}{|c|c|c|}
\hline \multirow[b]{2}{*}{ Odor } & \multicolumn{2}{|c|}{ Participants $(n=124)$} \\
\hline & $\begin{array}{c}\text { Correct } \\
\text { answer (no) }\end{array}$ & $\%$ \\
\hline Pizza & 59 & 47.6 \\
\hline Gum & 91 & 73.4 \\
\hline Peppermint oil & 119 & 96.0 \\
\hline Fish & 4 & 3.2 \\
\hline Motor oil & 41 & 33.1 \\
\hline Mint & 124 & 100.0 \\
\hline Banana & 124 & 100.0 \\
\hline Clove & 124 & 100.0 \\
\hline Leather & 114 & 91.9 \\
\hline Coconut & 124 & 100.0 \\
\hline Onion & 124 & 100.0 \\
\hline Drink fruit & 78 & 62.9 \\
\hline Children powder & 124 & 100.0 \\
\hline Cheese & 55 & 44.4 \\
\hline Cumin & 110 & 88.7 \\
\hline Benzene & 82 & 66.1 \\
\hline Strawberry & 119 & 96.0 \\
\hline Garlic & 124 & 100.0 \\
\hline Chocolate & 119 & 96.0 \\
\hline Walnut & 114 & 91.9 \\
\hline Grapefruit & 59 & 47.6 \\
\hline Rubber framework & 124 & 100.0 \\
\hline Peach & 124 & 100.0 \\
\hline Coffee & 36 & 29.0 \\
\hline Dill pickle & 18 & 14.5 \\
\hline Pineapple & 110 & 88.7 \\
\hline Apple & 91 & 73.4 \\
\hline Orange & 124 & 100.0 \\
\hline Pine & 45 & 36.3 \\
\hline Watermelon & 119 & 96.0 \\
\hline Jasmine flower & 87 & 70.2 \\
\hline Grass & 114 & 91.9 \\
\hline Smoke & 96 & 77.4 \\
\hline Cardamom & 91 & 73.4 \\
\hline Grape & 119 & 96.0 \\
\hline Lemon & 87 & 70.2 \\
\hline Soap & 119 & 96.0 \\
\hline Natural gas & 124 & 100.0 \\
\hline Rose & 101 & 81.5 \\
\hline Peanut & 124 & 100.0 \\
\hline
\end{tabular}

Shadowed Items have been identified by lee than $70 \%$ of the study subjects 
Table 3: Comparison between males and females of the study sample regarding UPSIT and VAS scores:

\begin{tabular}{lcccc}
\hline Test & $\begin{array}{c}\text { Male }(\mathrm{n}=37) \\
\text { Mean } \pm \text { SD }\end{array}$ & $\begin{array}{c}\text { Female }(\mathrm{n}=87) \\
\text { Mean } \pm \mathrm{SD}\end{array}$ & t test & P value \\
\hline UPSIT & $31.89 \pm 1.21$ & $31.32 \pm 1.90$ & 1.99 & $0.049^{*}$ \\
VAS & $7.13 \pm 0.34$ & $7.12 \pm 0.66$ & 0.09 & 0.924 \\
\hline *: significant & & & \\
UPSIT: University of Pennsylvania Smell Identification Test \\
VAS: Visual Analog Scale
\end{tabular}

Table 4: Item analysis of University of Pennsylvania Smell Identification Test:

\begin{tabular}{|c|c|c|}
\hline & $\begin{array}{l}\text { Corrected Item- } \\
\text { Total Correlation }\end{array}$ & $\begin{array}{l}\text { Cronbach's Alpha } \\
\text { if Item Deleted }\end{array}$ \\
\hline Pizza & 0.102 & 0.756 \\
\hline Gum & 0.343 & 0.737 \\
\hline Peppermint oil & 0.309 & 0.743 \\
\hline Fish & 0.086 & 0.749 \\
\hline Motor oil & 0.585 & 0.718 \\
\hline Leather & 0.043 & 0.752 \\
\hline Drink fruit & 0.258 & 0.743 \\
\hline Cheese & 0.617 & 0.714 \\
\hline Cumin & 0.099 & 0.751 \\
\hline Benzene & 0.230 & 0.745 \\
\hline Strawberry & 0.076 & 0.750 \\
\hline Chocolate & 0.309 & 0.743 \\
\hline Walnut & 0.457 & 0.734 \\
\hline Grapefruit & 0.442 & 0.729 \\
\hline Coffee & 0.223 & 0.746 \\
\hline Dill pickle & 0.326 & 0.739 \\
\hline Pineapple & -0.098 & 0.760 \\
\hline Apple & 0.520 & 0.724 \\
\hline Pine & 0.338 & 0.737 \\
\hline Watermelon & 0.027 & 0.751 \\
\hline Jasmine flower & 0.442 & 0.730 \\
\hline Grass & 0.248 & 0.745 \\
\hline Smoke & 0.490 & 0.727 \\
\hline Cardamom & 0.321 & 0.739 \\
\hline Grape & 0.086 & 0.749 \\
\hline Lemon & 0.216 & 0.746 \\
\hline Soap & 0.319 & 0.743 \\
\hline Rose & -0.056 & 0.762 \\
\hline
\end{tabular}

Each of the following component variables has zero variance and is removed from the scale: Mint, Banana, Clove, Coconut, Onion, Children powder, Garlic, Rubber framework, Peach, Orange, Natural gas, Peanut. The determinant of the covariance matrix is zero or approximately zero. Statistics based on its inverse matrix cannot be computed and they are displayed as system missing values.

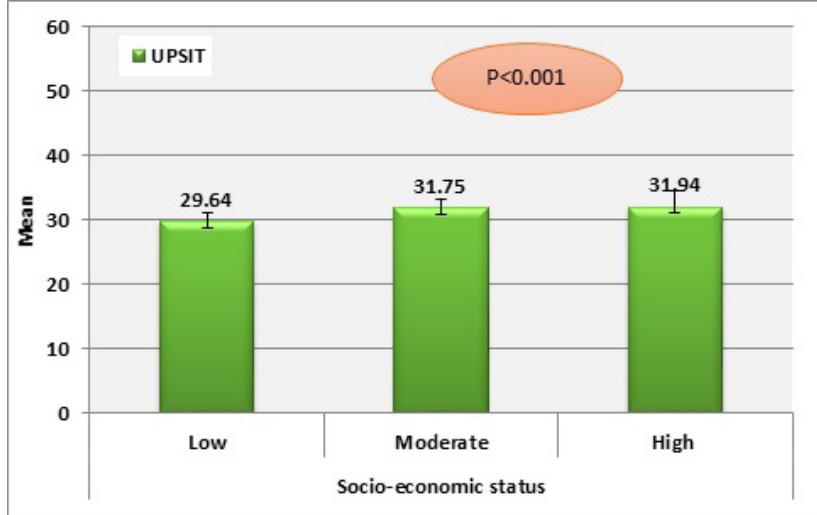

Fig. 2: Distribution of UPSIT score according to socio-economic status

\section{DISCUSSION}

University of Pennsylvania Smell Identification test is a well-recognized and validated tool for assessment of olfactory function in different diseases. It has been developed by Sensonics Inc and translated into different languages including Arabic language with modifications of the included odorants to be applicable for different nations. The Arabic version of UPSIT was created by changing the language and odors to be more familiar for Arab nation. Up to our best knowledge, this Arabic version has only been validated for Saudi subjects by Albaharna et a ${ }^{[6]}$. This is the first study to assess the validity of UPSIT for Egyptian population. In the current study, the mean UPSIT score was 31.49. It is higher than the mean score among the Saudi population which was 28.4. This suggests more applicability of the test for the Egyptian population. This can be attributed to more popularity of the odorants used in the test in Egypt. Compared to the test in other languages, the Egyptian score is higher than the score in Italian population $(\text { mean }=28.22)^{[9]}$. This can be attributed to high mean age and smoking index among included sample of Italian population with consequent smell disorders including hyposmia. On the other hand, the score in our sample of Egyptian population is lower than the mean score in American and Australian populations when tested using the original version (mean $=36$ and 34, respectively). ${ }^{[10]}$ This score is lower than the mean score in the Brazilian, Taiwan, and Japanese populations (mean $=35,33.1$ and 34.9 , respectively), obtained when tested using the modified versions of UPSIT. ${ }^{[11-13]}$ This finding proposes the fact that the used odors to fit the cultural nature of Arab population are not totally appropriate for this purpose. Looking at the least identifiable odors, we found that fish odor was identified by $3.2 \%$ of subjects and dill pickle was identified by $14.5 \%$. Nearly all the study population commented that the fish odorant was too weak and unidentifiable. The dill pickle odorant was not familiar 
for most of the study subjects. However, although coffee is a common drink in Egypt, only $29 \%$ of the sample identified this odor. This poses a question about the odorant concentration in the microcapsules. Motor oil was identified by $33.1 \%$ of the sample. This can be attributed to the fact that this odor is related to car driving which is not the rule for every subject especially with $70.2 \%$ of the sample being females with car driving being uncommon among females in the Egyptian community. Pine odor was identified by only $36.3 \%$ of our sample. This can be attributed to the limited areas of pine trees in Egypt. Pine trees are common in other Arab countries like Lebanon, so its inclusion in the Arabic version of UPSIT is acceptable. The Arabic Culture has a lot of diversities between different countries and regions, and what works for some countries might not work for others. Some odors in the English version which has been replaced by other odors in the Arabic version (e.g. Cinnamon and cheddar cheese), are well known in Egypt and their replacement with other odors was not convenient. UPSIT was higher among males than females with little significance. This disagrees with Albaharna et $a l^{[6]}$ who reported that women scored significantly better than men. Picillo et $a l^{[9]}$ in their Italian study fouund that women's mean scores were higher than those in men without reaching a statistically significant difference. This difference can be attributed to different sample sizes. Sorokowski et $a l^{[4]}$ in their meta-analysis stated that the significant, difference between both genders is small and leads to very low absolute differences in olfactory test performance. Participants with high and moderate socio-economic standard reported significantly higher UPSIT than those with low socio-economic standard. This was against the results of Fornazieri et $a l^{[10]}$ who assessed the validity of UPSIT in a sample of Brazilian population. They graded their sample according to income levels. They found that, all participants successfully took the test, including subjects of lower income levels. There were no statistically significant differences among subjects of different income levels. This difference can be attributed to the fact that socioeconomic status includes factors other than the income level like educational level. The Cronbach's $\alpha$ value in our study was 0.749 which is higher than the Saudi alpha value of $0.681^{[6]}$. This matches the higher UPSIT score in the Egyptian sample compared with the Saudi sample. The limitations of our study include the unequal distribution of study subjects between males and females for more precise comparison between males and females regarding UPSIT score. Also, our study did not take in consideration the possible variation in olfactory experience between different regions in Egypt like, delta, Upper Egypt and coastal areas. Also, the test was applied to the residents of a single city with possible variation between different cities in the same area.

\section{CONCLUSION}

The Arabic version of UPSIT is an adequate tool for assessment of olfaction in the Egyptian population. Males and higher socioeconomic levels were associated with better test results. But 9 Odorants of this test needs further assessment for the need of replacement with more familiar odors or concentration adjustment. Further studies are required in different countries of the Arab nation to reach a consensus about the odorants that are not appropriate for the Arabic version of UPSIT. This can be a basis for contacting the manufacturing company and requesting a modification in the Arabic version of the test to be more culturally adaptable. Also, preparation of a specific test for every country should be considered by the manufacturer to meet the cultural variation between different Arabic countries.

\section{CONFLICT OF INTEREST}

There are no conflicts of interest.

\section{REFERENCES}

1. Doty RL, Shaman P, Dann M. Development of the University of Pennsylvania Smell Identification Test: a standardized microencapsulated test of olfactory function. Physiol Behav. 1984; 32:489-502.

2. Doty RL. The Smell Identification Test TM administration manual. Haddon Heights, NJ: Sensonics Inc. 1995.

3. Doty RL, Kamath V. The influences of age on olfaction: a review. Front Psychol. 2014; 5:20.

4. Sorokowski P, Karwowski M, Misiak M, Marczak MK, Dziekan M, Hummel T, et al. Sex Differences in Human Olfaction: A Meta-Analysis. Front Psychol. $2019 ; 10: 242$.

5. Calderón-Garcidueñas L, Franco-Lira M, HenríquezRoldán C, Osnaya N, González-Maciel A, ReynosoRobles $\mathrm{R}$, et al. Urban air pollution: influences on olfactory function and pathology in exposed children and young adults. Exp Toxicol Pathol. 2010; 62(1):91-102.

6. Albaharna $\mathrm{H}$, Almubaireek $\mathrm{H}$, Upadhyay $\mathrm{S}$, Buohliqahaet L. Validity of the Arabic version of the University of Pennsylvania smell test on a Saudi population. Pan Arab Journal of Rhinology Journal 2017, 7:7-10.

7. Doty RL. Olfaction. Annu Rev Psychol. 2001; 52:423-452. 
8. Fahmy SI, Nofal LM, Shehata SF, El Kady HM, Ibrahim HK. Updating indicators for scaling the socioeconomic level of families for health research. J Egypt Public Health Assoc. 2015; 90(1):1-7.

9. Picillo M, Iavarone A, Pellecchia MT, Amboni M, Erro $\mathrm{R}$, Moccia $\mathrm{M}$, et al. Validation of an Italian version of the 40-item University of Pennsylvania Smell Identification Test that is physician administered: our experience on one hundred and thirty-eight healthy subjects. Clin Otolaryngol. 2014; 39(1):53-7.

10. Mackay-Sim A, Doty RL. The University of Pennsylvania Smell Identification Test: normative adjustment for Australian subjects. Aust J Otolaryngol. 2001; 4:174-177.
11. Fornazieri MA, Doty RL, Santos CA, Pinna Fde R, Bezerra TF, et al. Voegels RL. Anew cultural adaptation of the University of Pennsylvania Smell Identification Test. Clinics (Sao Paulo). 2013; 68(1):65-8.

12. Jiang RS, Su MC, Liang KL, Shiao JY, Wu SH, Hsin $\mathrm{CH}$. A pilot study of a traditional Chinese version of the University of Pennsylvania Smell Identification Test for application in Taiwan. Am J Rhinol Allergy. 2010; 24(1):45-50.

13. Ogihara H, Kobayashi M, Nishida K, Kitano M, Takeuchi K. Applicability of the cross-culturally modified University of Pennsylvania Smell Identification Test in a Japanese population. Am J Rhinol Allergy. 2011; 25(6):404-410. 